\title{
A percepção do idoso sobre a vacina contra influeza
}

Recebido em: 19/01/2011

Aceito em: 14/04/2011

Diana Nascimento e Santos ${ }^{1}$

Suéli Nolêto Silva Sousa ${ }^{2}$

Dâmaris Rebeca Soares da Silva ${ }^{3}$

Maria do Livramento Fortes Figueiredo ${ }^{4}$

O estudo tem uma abordagem quantiqualitativa e foi realizado com 109 idosos residentes em Timon-MA. Objetivou-se conhecer a percepção do idoso acerca da vacina contra influenza, identificar a aceitação da vacina e descrever como interpretam informações da campanha de vacinação. Observou-se que a participação na campanha de 2008 está abaixo do preconizado pelo Ministério da Saúde e que, entre os que se vacinaram, a maioria sentiu-se satisfeita com os efeitos da vacina.

Descritores: Idoso, Vacinação, Influenza Humana.

\section{The perception of the elderly people about influenza vaccine}

The study is based on a quanti-qualitative approach, and was conducted with 109 elderly residents in Timon-MA. It was intended to find out the perception of the elderly about the influenza vaccine, identify acceptance of the vaccine and to describe how to interpret information about the vaccination campaign. It was noticed that the participation in the campaign of 2008 didn't have the effects that were expected by the Ministry of Health and that among the vaccinated ones, most felt satisfied with the effects of the vaccine.

Descriptors: Elderly, Vaccination, Human Influenza.

\section{La percepción de los ancianos en la vacuna contra la influeza}

El estudio posee abordaje cuanti-cualitativa y fue realizado con 109 ancianos residentes en Timon-MA. Tuvo como objetivos conocer la percepción del anciano acerca de la vacuna contra influenza; identificar aceptación de la vacuna y describir como interpretan informaciones de la Campaña de Vacunación. Se observó que la participación en la campaña de 2008 está abajo del preconizado por el Ministerio de Salud y que entre los que tomaron la vacuna, la mayoria se sentió satisfecha con los efectos de ella.

Descriptores: Anciano, Vacunación, Influenza Humana.

\section{INTRODUÇÃO}

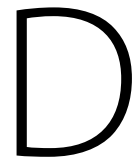
urante as últimas décadas, as mudanças nos indicadores sociais, como a diminuição na taxa de mortalidade e fecundidade, tornaram-se fatores decisivos para o aumento da população idosa. Entretanto, à medida que a população envelhece, observase um aumento da fragilidade do indivíduo em decorrência do abaixamento da imunidade do organismo, tornando-o vulnerável a diversas doenças. Entre essas, destaca-se a gripe (ou influenza), que traz sérias complicações ao idoso.

A gripe é uma doença infecciosa viral, contagiosa, relacionada ao comprometimento do trato respiratório. Quando ela se manifesta em um indivíduo com boa resistência imunológica, torna-se uma patologia de pouca relevância. Porém, é uma doença que se dissemina rapidamente e apresenta elevada morbimortalidade em grupos de maior vulnerabilidade ${ }^{(1)}$.

Como medida de prevenção à influenza, desde 1999, o Ministério da Saúde do Brasil (MS) decidiu investir na mobilização da população idosa para que essa desfrutasse os benefícios das vacinações, direcionadas aos maiores de 65 anos. Porém, a partir de 2000 , ofertou-se a vacina àqueles com idade acima de 60 anos $^{(2)}$.

A principal estratégia para reduzir a morbimortalidade por doenças respiratórias em idosos é a cobertura vacinal contra a influenza de, no mínimo, $80 \%$ da população-alvo (e a manutenção desses índices ao longo dos anos) $)^{(3)}$. O idoso é o alvo da campanha por representar a faixa etária em que há maior índice de internações e óbitos decorrentes de complicações advindas da gripe.

Apesar da divulgação e do incentivo por parte do governo federal, ainda é comum a resistência de pessoas idosas em relação à vacina por motivos como a presença de efeitos colaterais, dúvidas relacionadas à eficácia da vacina ou ainda falhas na divulgação dessa em determinados locais. Identificouse, no bairro Parque Piauí, na cidade de Timon-MA, um número significativo de idosos assistidos pela Estratégia Saúde da Família (ESF), o que nos instigou a levantar o conhecimento, a

1 Acadêmica do curso de Enfermagem da Universidade Federal do Piauí - UFPI, Teresina-PI. E-mail: diana.enfermagem@gmail.com

2 Enfermeira, graduada pela Universidade Federal do Piauí - UFPI, Teresina-PI.

3 Enfermeira, graduada pela Universidade Federal do Piauí - UFPI, Teresina-PI.

4 Enfermeira. Doutora em Enfermagem. Docente do Departamento de Enfermagem da Universidade Federal do Piauí -UFPI, Teresina-PI. 
atitude, os mitos e preconceitos desses idosos sobre a vacina contra influenza.

"Percepção" deve ser entendida como o ato de perceber, a ação de formar mentalmente representações sobre objetos externos a partir dos dados sensoriais. A percepção constitui-se na decodificação dos estímulos recebidos e pode ser descrita como a maneira com que se vê o mundo em volta, ou seja, o modo através do qual o indivíduo constrói em si o conhecimento e a representação das pessoas, coisas e situações ${ }^{(4)}$. Portanto, visando a descrever a percepção dos idosos sobre a vacina contra influenza, foram elaborados os seguintes objetivos para essa investigação: conhecer a percepção do idoso acerca da vacina contra influenza; identificar a aceitação ou rejeição por parte dos idosos em relação à vacina contra influenza; descrever como os idosos dessa comunidade interpretam as informações da Campanha Nacional de Vacinação contra a Gripe.

\section{METODOLOGIA}

Trata-se de um estudo exploratório descritivo, com abordagem quantiqualitativa, que se caracterizou como uma pesquisa de campo financiada pelo Programa de Bolsa de Iniciação Científica/UFPI. A coleta de dados foi realizada com os idosos cadastrados na Equipe da Estratégia Saúde da Família (ESF) do bairro Parque Piauí, situado na cidade de Timon-MA. O tamanho amostral foi calculado pela amostragem aleatória simples, tomandose por base a população de idosos da área da ESF em estudo $(n=150)$, com um erro tolerável de $5 \%$ e intervalo de confiança de $95 \%$. Assim, encontrou-se uma amostra de 109. A técnica utilizada foi a entrevista domiciliar com aplicação do formulário previamente elaborado.

Em se tratando da análise qualitativa, tomou-se o discurso de 65 idosos em decorrência da saturação das falas. Foi preservado o anonimato dos sujeitos, e os homens foram representados por "H" e as mulheres por "M", ambos numerados por cronologia de entrevista. Os dados seguiram a análise de conteúdo.

A pesquisa foi aprovada pelo Comitê de Ética em Pesquisa da UFPI (Parecer no 0095.0.045.000-08). Todos os sujeitos foram consultados e esclarecidos sobre a participação na citada investigação, com leitura e assinatura do Termo de Consentimento Livre e Esclarecido, elaborado de acordo com a Resolução 196/96 do CNS/MS.

\section{RESULTADOS}

Dos 109 idosos pesquisados, 89 deles $(81,6 \%)$ estão na faixa etária entre 60 e 79 anos e 20 idosos (18,4\%) têm entre 80 e 100 anos de idade; 71 entrevistados $(65,1 \%)$ representam o sexo feminino e 38 idosos (34,9\%) correspondem ao sexo masculino. Com relação à escolaridade, 39,5\% (43 idosos) afirmam serem analfabetos e 58 idosos (53,2\%) afirmam possuir o ensino fundamental incompleto. Dois idosos possuem o ensino médio incompleto e dois possuem o ensino médio completo.

Considerando a renda, concluiu-se que 70 idosos $(64,2 \%)$ recebem até um salário mínimo $(\mathrm{SM})$; seis recebem mais de dois SM; 12 não informaram a renda. Diante da situação conjugal, 64 idosos (58,7\%) são casados e 33\% (36 idosos) são viúvos, quatro idosos são separados e cinco são solteiros.

Dos 109 entrevistados, 45 idosos (41,3\%) não aderiram à Campanha de Vacinação de 2008, enquanto 64 idosos (58,7\%) tomaram a vacina contra influenza em 2008; 58 mulheres e 33 homens afirmam ter pretensão de participar nas próximas campanhas; 18 idosos não têm pretensão de participar da próxima campanha anual; 95 idosos $(87,2 \%)$ acreditam na eficácia da vacina, contra 14 idosos (12,8\%) que foram contrários; 69 idosos não acreditam no aparecimento de efeitos colaterais após a vacinação, enquanto 40 idosos acreditam no aparecimento de efeitos como febre baixa e dor no local da vacina.

Na análise qualitativa, formaram-se três categorias de análises: 1) aceitação positiva da vacina contra influenza; 2) dificuldades de adesão à vacina contra influenza; 3) desconfianças e boatos negativos sobre a vacina contra influenza.

\section{DISCUSSÃO}

Quanto à faixa etária, predominaram os idosos com idades entre 60 e 79 anos, equivalendo a $89 \%$ dos idosos. Conforme os dados do Censo 2000, o grupo das pessoas de 75 anos ou mais de idade teve o maior crescimento relativo $(49,3 \%)$ nos últimos dez anos em relação ao total da população idosa ${ }^{(5)}$.

Segundo a distribuição por escolaridade, verificou-se que tais resultados podem ser atribuídos às características da sociedade e às políticas de educação prevalecentes nas décadas de 1930 e 1940, quando o acesso à escola era ainda muito restrito ${ }^{(6)}$.

O quesito renda mostra que os idosos aposentados representam um dos segmentos sociais com maior estabilidade, tornando-se crescente o número de casos em que esses se responsabilizam pela manutenção de suas famílias ${ }^{(7)}$.

Em se tratando de gênero, a feminização da velhice é identificada em vários estudos estatísticos e demográficos. Ela está evidente no maior número de mulheres entre os idosos, representando mais da metade da população idosa. Esse fato é explicado por conta das diferenças na exposição aos riscos ocupacionais; maiores taxas de mortalidade por causas externas entre os homens; diferenças no consumo de tabaco e álcool e nas diferenças de atitudes em relação às doenças, ou seja, as mulheres utilizam os serviços de saúde com maior frequência ${ }^{(8)}$.

Atualmente, preconiza-se a vacinação contra influenza a $80 \%$ da população idosa(3). Relacionando tal fato com a amostra pesquisada, é importante ressaltar a inclusão da população diante da Campanha Nacional de Vacinação de 2008, fazendo- 
se notar 58,7\% de vacinação em uma amostra de 109 idosos.

Em relação à expectativa de adesão às próximas campanhas, nota-se que, apesar da divulgação das campanhas e dos benefícios da vacinação, muitos idosos ainda não aderiram a essa prática no país. Isso se deve à existência de inúmeros fatores que interferem na adesão dos idosos à vacinação contra influenza, como medo, má ou insuficiente informação, falta de motivação e até crendices e tabus ${ }^{(9)}$.

Em se tratando do aparecimento de efeitos colaterais decorrentes da vacinação, como febre baixa e dor no local da vacina, é sabido que a efetividade da vacina contra influenza para prevenir ou atenuar os efeitos da gripe, bem como a reação da vacina no organismo do idoso, depende da idade, da imunidade do paciente e do grau de similaridade entre as linhagens virais incluídas nas vacinas e as que circulam durante a temporada de influenza ${ }^{(10)}$.

$\mathrm{Na}$ análise qualitativa, formaram-se três categorias referentes à percepção dos idosos sobre a vacina contra influenza:

\section{1) Aceitação positiva da vacina contra influenza}

A aceitação positiva da vacina mostrou-se significativa nos depoimentos de grande parte dos sujeitos, mostrando os resultados tanto das campanhas da mídia quanto das ações dos serviços locais de saúde. As falas a seguir evidenciam a percepção positiva, representando a adesão desses idosos à vacinação contra gripe:

[...] Essa vacina é mais do que boa, é ótima, maravilhosa! [...] (Depoentes: M14, M23, M26, M35, M43, H16).

[...] Acho importante a vacina, porque antes eu gripava muito, depois da vacina não fico gripando [...] (Depoentes: M28, M29, M30, M31, H11, H12, H13, H14, H15, H27).

[...] Depois que eu comecei a me vacinar das vezes que tive gripe ela veio mais fraca [...] (Depoentes: H1, H8, M4, M10, M12, M19, M38).

No que diz respeito aos efeitos da vacina no organismo, constatou-se que muitos idosos reconhecem a importância da vacina ao relatarem satisfação, bem-estar e por não griparem após a vacinação. Isso revela que a vacina está trazendo bons resultados dentro da população-alvo, o que aumenta a chance de adesão às próximas campanhas.

Enfatizando novamente esse aspecto, encontraram-se falas retratando a incidência de gripe após a vacinação, porém menos severa. Nesse contexto, o MS divulgou que a vacina provê proteção de aproximadamente $50 \%$ dos idosos vacinados, significando que esses apresentam imunidade parcial, reduzindo a possibilidade de adquirirem as formas mais graves da enfermidade ${ }^{(3)}$.

\section{2) Dificuldades de adesão à vacina contra influenza}

Apesar de a maioria dos idosos expressar adesão positiva à vacinação, ainda se pode considerar o percentual de 41,3\% de não-aceitação extremamente significativo para uma prática preventiva de comprovada importância.

Os discursos a seguir mostram a descrença ou a não-aceitação de idosos à vacinação contra gripe:

[...] Eu tomei a vacina e depois tive uma gripe forte [...] (Depoentes: M1, M6, M7, M8, M11, M25, M33, M43, H4, H17).

[...] Eu não acredito nessa vacina, não acho boa [...] (Depoentes: $M 13, M 17, H 2)$.

[...] Eu acho que os outros podem tomar; não dá é pra mim [...] (Depoentes: M14, M23, M26, M35, M43, H16).

É importante reforçar que a vacina não previne a doença em $100 \%$ dos indivíduos vacinados; porém, pode reduzir o risco das sérias complicações advindas dessa enfermidade, como as pneumonias e, principalmente, os óbitos. Constituindo-se, portanto, no maior objetivo da vacinação para a população idosa, mostra a necessidade de mais ações que impliquem em uma maior adesão dos idosos à Campanha de Vacinação(11).

Outro fator relevante na resistência à vacinação é a insegurança do idoso, demonstrada na presença do medo de "reações" decorrentes da vacina. Porém, o MS afirma que não há como a vacina provocar gripe, porque ela não contém vírus vivos. É uma vacina em que os vírus estão mortos e atenuados, e, caso realmente ocorra algum episódio de gripe, osfatoresque poderiam estar acontecendo seriam uma resposta imunológica à vacina insuficiente ou contaminação com o vírus da gripe anteriormente ao período de proteção promovido pela vacina ${ }^{(11)}$. Outros estudos reafirmam que a vacina é bastante segura, mas mostram alguns efeitos comuns, tais como febre baixa em aproximadamente $30 \%$ dos vacinados, dor e eritema no local da vacina, que podem ocorrer no primeiro e segundo dias e durar até dois dias ${ }^{(10)}$.

Dentro desse contexto, em que os idosos afirmam a presença de gripe forte após a vacinação ou outras reações, ocorre a descrença na vacina e a procedente não-adesão do idoso às campanhas de vacinação.

Assim, é importante melhorar as ações educativas nessa área, visto que o surgimento de sintomas pós-vacinais do tipo gripe não são consequência da vacina contra influenza, como foi exposto anteriormente.

\section{3) Desconfianças e boatos negativos sobre a vacina contra influenza}

As declarações a seguir afirmam a presença ou a ausência de contrainformações sobre a vacina na população estudada:

[...] Não, nunca ouvi boato não [...] (Depoentes: M1, M6, M 7, M8, M11, M25, M33, M43, H4, H17).

[...] Tem idoso que diz que essa vacina foi o governo que fez para matar os velhos. Mas não acredito nisso [...] (Depoentes: M10, 
M18, M 22, M28, M31, M34, M39, M42, M43, H7, H10, H12, H20).

Considerando as ideias ouvidas pelos idosos sobre a vacina, encontramos muitos discursos que apresentavam posicionamento negativo dos idosos acerca da vacina. Portanto, pode-se enfatizar a necessidade de melhores esclarecimentos e de eficientes formas de divulgação dos benefícios da vacina para os idosos, para reduzir as ideias negativas e também aumentar a adesão à campanha de vacinação.

Dessa forma, nota-se a existência de imprecisões nas opiniões dos idosos sobre a vacina, o que motiva a resistência e traz dificuldades à execução da campanha. Um exemplo é a contrainformação divulgada no imaginário coletivo, segundo a qual o governo utilizaria a vacina contra influenza com finalidade de matar os idosos e assim reduzir o número de aposentados.

Essa desconfiança se propagou em meio a população em geral e ainda hoje se mantém como um obstáculo à adesão à campanha, como pode ser observado em alguns depoimentos, a exemplo de M10, que diz: "Eu já ouvi boato [...] tinha uma mulher que morava lá perto de casa que me perguntava se eu ia tomar a vacina e dizia: 'Não vá não, porque o presidente tá dando pra matar os véis [risos]"'. Felizmente, alguns idosos que referiram escutar boatos negativos a respeito da vacina não acreditavam nas críticas.

Considerando-se os pensamentos e o grau de conhecimento da população, reforça-se a importância das práticas educativas em saúde, baseadas na comunicação e nos esquemas de abordagem aos idosos, utilizadas pelos profissionais da saúde e por meios de comunicação em período de divulgação da campanha, informando corretamente a população quanto aos benefícios à saúde do idoso.

\section{CONCLUSÃO}

A presente pesquisa possibilitou a visão da percepção de uma população idosa apta a participar da campanha de vacinação contra influenza. Mostrou a necessidade da atenção dos profissionais da saúde, especialmente os da enfermagem, bem como da mídia, para que sejam mais eficazes no sentido de atrair a população idosa, e, assim, sempre viabilizar o aumento da cobertura vacinal preconizado pelo Ministério da Saúde. Isso proporcionará um envelhecimento saudável, tendo em vista a melhoria da qualidade de vida resultante dos efeitos positivos da vacina contra influenza.

\section{Referências}

1. Pessoni A, Cudizio FFP, Machado MP, Zing NPC, Bes PC, Mattos RTB. Pesquisa local sobre o impacto da comunicação na campanha nacional da vacinação de idosos contra a gripe. In: Anais do $30^{\circ}$ Congresso Brasileiro de Ciências da Comunicação; 2007; Santos, Brasil [Internet]. [citado em 2009 Jan 12]. Disponivel em: http://www.intercom.org.br/papers/nacionais/2007/resumos/R1159-1.pdf. 2. Ministério da Saúde (BR). Secretaria de Vigilância em Saúde. Informe técnico da Campanha de Vacinação do Idoso. Rio de Janeiro: Ministério da Saúde; 2006. 3. Ministério da Saúde (BR). Secretaria de Vigilância em Saúde. Informe técnico da Campanha de Vacinaçăo do Idoso. Rio de Janeiro: Ministério da Saúde; 2008. 4. Japiassu H, Marcondes D. Dicionário básico de filosofia. $2^{2}$ ed. Rio de Janeiro: Jorge Zahar; 1993.

5. Instituto Brasileiro de Geografia e Estatísticas. Censo demográfico 2000 [Internet]. [citado em 2008/2009]. Disponivel em: http://www.lbge.gov.br/home/ presidencia/noticias.

6. Ministério do Planejamento, Orçamento e Gestão (BR). Perfil dos idosos responsáveis pelos domicílios no Brasil 2000. Rio de Janeiro: Ministério do Planejamento, Orçamento e Gestão; 2002. p. 97.

7. Coutrim RME. Idosos trabalhadores: perdas e ganhos nas relaçōes intergeracionais. Soc Estado. 2006;21(2):367-90.

8. Feliciano AB, Moraes AS, Freitas ICM. O perfil do idoso de baixa renda no Município de São Carlos, São Paulo, Brasil: um estudo epidemiológico. Cad Saúde Pública. 2004;20(6):1575-85.

9. Ozaki LMTR, Shimo AKK, Guirardello EB, Araujo IE. O Papel do enfermeiro para minimizar riscos nas imunizaçōes. Nursing (São Paulo). 2004;79(7):24-8.

10. Cação JC, Godoy MRP, Villas Boas PJF. Vacinação em idosos: dados atuais. In: Anais do $3^{\circ}$ Congresso Paulista de Geriatria e Gerontologia, 2003, Santos, Brasil. Santos: 3० GERP, 2003. p. 21.

11. Ministério da Saúde (BR). Secretaria de Vigilância em Saúde. Informe técnico da Campanha de Vacinação do Idoso. Rio de Janeiro: Ministério da Saúde; 2005. 